\title{
PERANCANGAN BUKU RESEP 30 IKON KULINER TRADISIONAL INDONESIA UNTUK GENERASI MUDA
}

\author{
Carol Nathalie Serenami, Rene Arthur Palit \\ (E-mail: rolznathalie@yahoo.com) \\ Desain Komunikasi Visual \\ Fakultas Seni Rupa dan Desain \\ Universitas Kristen Maranatha \\ Jl. Prof. Drg. Surya Sumantri No.65, Bandung, Indonesia.
}

\begin{abstract}
ABSTRAK
Indonesia adalah negara yang kaya dengan beragam aspek budaya.Kuliner Indonesia mewarisi citarasa masakan tradisional paling beragam di dunia.Diperkirakan ragam kuliner tradisional Indonesia berjumlah lebih dari 5000 macam. Pada tahun 2012 Pemerintah Indonesia melalui Kementerian Pariwisata dan Ekonomi Kreatif (Kemenparekraf) telah mencanangkan 30 Ikon Kuliner Tradisional Indonesia (30 IKTI) yang merupakan representasi aset kuliner terbaik Indonesia. Resep dari 30 IKTlyang kaya akan rempah nusantara dan tahapan yang rumit sehingga menghasilkan keunikan citarasa khas Indonesiaperlu untuk didokumentasikan menjadi sebuah buku pegangan dengan informasi yang tepat. Hal tersebut secara tidak langsung akan memperkenalkan kuliner Indonesia lebih luas lagi, bahkan sampai ke ranah Internasional. Terpengaruh dengan gaya hidup modern, generasi muda Indonesia saat ini lebih tertarik dengan kuliner khas asal manca negara daripada kuliner lokal. Mereka belum mengakui kuliner khas Indonesia sebagai kebanggaannya. Beberapa buku yang memperkenalkan 30 ikon kuliner Indonesia telah diterbitkan, namun untuk lebih memperkaya pustaka yang berisi tentang 30 ikon kuliner Indonesia, dirancanglah sebuah buku tentang 30 ikon kuliner Indonesia dengan gaya dan visualisasi berbeda dari yang sudah ada. Buku ini dirancang dengan gayaJournal menyerupai sebuah catatan memasak, dengan penggabungan teknik ilustrasi dan fotografi. Perancangan ini juga dilengkapi dengan media pendukung seperti booklet, website, akun media sosial, dan keperluan book launching. Diharapkan melalui perancangan ini, generasi muda akan menjadi lebih tertarik dan bangga akan kuliner khas Indonesia sebagai salah satu warisan budayanya.
\end{abstract}

Kata Kunci: buku resep; generasi muda; ilustrasi; ikon kuliner; Indonesia

\begin{abstract}
Indonesia is an archipelago witha high diversity. As a country with various cultural aspects, Indonesia inherits the most diverse traditional dishes. It is estimated that there are over 5,000 kinds of Indonesian dishes. In 2012 the Indonesian government, through the Ministry of Tourism and Creative Economy (Kemenparekraf), has launched 30 culinary icons that best represent Indonesia's best culinary assets. The recipes of the 30 Indonesian culinary icons and their complicated cooking stages need to be documented into a handbook. This handbook will indirectly introduce the culinary of Indonesia more broadly, even internationally. Influenced by the modern lifestyle, the Indonesian younger generation is currently more interested in the culinary of foreign countries rather than the local one. They have not admitted the Indonesian cuisine as their pride. Some books that introduce 30 Indonesian culinary icons have been published, but to further enrich the literature, another book about 30 Indonesian culinary icons is designed with styles and visuals different from the previous ones. The book is designed in a journal style to resemble a cooking record, with the incorporation of illustrations and photography. The design is also equipped by supporting medias such as booklets, websites, social media accounts, and the medias neededfor book launching. It is expected that through this design, the younger generation will become more interested and proud of Indonesia's unique cuisine as one of the cultural heritage.
\end{abstract}


Keywords: culinary icon; illustration; Indonesia; recipe book; young generation

\section{PENDAHULUAN}

Indonesia sebagai sebuah negara kepulauan terbesar di dunia memiliki tingkat kemajemukan yang sangat tinggi. Sebagai negara yang sangat kaya akan keragaman budaya, Indonesia mewarisi cita rasa masakan yang paling beragam di dunia. Jumlah kuliner tradisional Indonesia kurang lebih ada lebih dari 5000 kuliner. Dengan angka yang sangat besar, masyarakat Indonesia tidak bisa memilih kuliner spesifik sebagai ikon yang mewakili keseluruhan negara Indonesia, seperti layaknya negara Jepang dengan ikon sushi, negara Italia dengan ikon pizza atau pasta, dan Korea dengan kim chi. Sehingga pada akhir tahun 2012, Kementrian Pariwisata dan Ekonomi Kreatif mencanangkan 30 buah makanan tradisional yang akan menjadi ikon kuliner tradisional Indonesia yang diberi nama 30 Ikon Kuliner Tradisional Indonesia (30 IKTI). Menurut Bondan Winarno, sejak pencanangannya, upaya pelestarian $30 \mathrm{IKTI}$ yang dijanjikan Bekraf sampai saat ini masih belum jelas. Padahal, sebagai salah satu sub

sektor dalam perekonomian kreatif Indonesia, bidang kuliner adalah penyumbang terbesar dalam perekonomian Indonesia (sebesar 32,4 \%). (www.cnnindo nesia.com,2016). William Wongso, seorang pakar kuliner tradisional Indonesia, juga berpendapat bahwa Indonesia tidak banyak membuat usaha dalam upaya melestarikan tradisi kuliner Indonesia, berbeda dengan Thailand, Korea, dan Jepang yang menganggap bahwa makanan khasnya adalah kebanggaan bangsa (http://food.detik. com /read/2016). Dalam buku "Potret-Potret Gaya Hidup Metropolis" (Susanto: 2001) dijelaskan bahwa salah satu ciri gaya hidup modern adalah cara hidup instan. Manusia modern lebih memilih segalanya yang instan; serba cepat, praktis, dan efektif, sehingga makanan tradisional yang cara pembuatannya memerlukan waktu cenderung ditinggalkan. Ditambah dengan masuknya globalisasi ke Indonesia yang ditandai dengan munculnya gerai-gerai junkfood dan makanan-makanan instan yang otomatis menjadi pilihan generasi modern, sehingga dapat disimpulkan bahwa globalisasi dan perkembangan jaman mengakibatkan pemuda kurang tertarik pada budaya dan tradisi Indonesia yang dicap kuno dan ketinggalan jaman, walaupun sebenarnya minat pemuda Indonesia pada kuliner tradisional sangat tinggi. 


\section{METODE PENELITIAN \\ Buku Sebagai Media}

Menurut Kate Garland, seorang dosen psikologi University of Leicester, buku cetak berperan lebih besar dalam memberikan memori jangka panjang pada pembaca. Berdasarkan pengamatannya, pembaca yang membaca dari buku lebih menguasai topik yang dibaca dibandingkan dengan pembaca yang membaca dari e-book. Selain itu, manusia cenderung selalu menggunakan 'metode lokus', yaitu mengingat hal-hal yang berhubungan dengan tempat yang pernah dikunjungi. Oleh karena itu pembaca sering mengingat lokasi sesuatu yang dibacanya pada buku, contohnya di kiri atas halaman, atau kanan bawah halaman, atau tulisan yang diletakkan disebelah gambar (http://health. detik.com,2016).

\section{Buku Bergambar}

Buku bergambar adalah buku yang isi cerita dan pesannya disampaikan melalui teks dan ilustrasi atau gambar. Menurut Drs. Ngalim M. Purwanto, buku yang ditampilkan dalam bentuk gambar-gambar akan dapat lebih menarik perhatian dan kesukaan membaca setiap orang karena pada umumnya, orang lebih tertarik pada bahasa penyampaian secara visual daripada bahasa verbal (Purwanto: 2004).

\section{Ilustrasi}

Kata 'ilustrasi' menurut Kamus Besar Bahasa Indonesia, memiliki arti sebagai gambar, termasuk juga foto, lukisan yang berfungsi untuk membantu memperjelas isi buku, karangan, dan sebagainya; gambar, desain, atau diagram untuk penghias (halaman sampul dan sebagainya); (penjelasan) tambahan berupa contoh, bandingan, dan sebagainya untuk lebih memperjelas paparan (tulisan dan sebagainya).

Sigit Santoso dalam bukunya yang berjudul "Advertising Guide Book" menyatakan bahwa kata 'ilustrasi' berasal dari bahasa latin 'illustre' yang berarti menerangkan. Ilustrasi dapat berupa gambar, simbol, relief, atau bahkan musik yang bertujuan untuk mengkomunikasikan serta menjelaskan sesuatu.Ilustrasi memiliki tiga fungsi, yaitu ilustrasi sebagai dekorasi, ilustrasi sebagai informasi, dan ilustrasi sebagai opini atau komentar yang sulit dijelaskan melalui tulisan (Santoso,2002:57). 


\section{Jenis Ilustrasi Berdasarkan Corak dan Bentuknya}

Ilustrasi dapat digolongkan dalam berbagai kategori. Margono \& Aziz (2010) membuat pembagian ilustrasi berdasarkan corak dan bentuk, yakni corak realistis, dekoratif, karikaturis, dan ekspresionis. Berbagai corak ilustrasi yang disebutkan ini masing-masing memiliki derajat kedekatan gambar dengan objek yang direpresentasikannya.Corak Realistis merupakan gaya ilustrasi yang paling mirip dengan wujud aslinya. Pada corak Dekoratif, ilustrator melakukan stilasi bentuk, namun tanpa meninggalkan ciri khas atau karakter bentuk aslinya. Selanjutnya, pada corak Karikaturistik, ilustrator melakukan deformasi dengan melebih-lebihkan sebagian tubuh/objek untuk memperkuat karakter tertentu, sedangkan pada corak Ekspresionis merupakan gaya ilustrasi yang paling jauh dari wujud aslinya. llustrator mendistorsi bentuk untuk mengekspresikanemosi tertentu. (http://eprints.uny.ac.id,2016)

\section{Still life photography}

Kata photography berasal dari bahasa Yunani 'photos' yang berarti cahaya dan 'grapho' yang berarti melukis atau menulis. Sehingga definisi dari fotografi adalah proses atau metode menghasilkan gambar atau foto dengan merekan pantulan cahaya yang mengenai suatu objek. Prinsip fotografi adalah memfokuskan cahaya dengan bantuan pembiasan sehingga mampu membakar medium penangkap cahaya. Medium yang telah dibakar dengan ukuran luminitas cahaya yang tepat akan menghasilkan bayangan identik dengan cahaya yang memasuki medium pembiasan (http://www.sjm.sch. Id, 2016)

Suhadha dan Fatah menjelaskan secara singkat tentang Still life photography adalah salah satu Jenis fotografi yang objeknya adalah benda-benda yang diam. Objek didandani sedemikian rupa agar terlihat hidup. Dalam Still life photography terdapat tiga hal yang penting untuk diperhatikan agar gambar yang dihasilkan tampak lebih hidup, yaitu: pencahayaan, komposisi, dan properti. Pencahayaan yang baik akan didapat saat mata fotografer peka terhadap cahaya yang muncul, sehingga lama kelamaan fotografer akan menguasai pengaturan cahaya yang diperlukan dalam sebuah sesi pemotretan. Komposisi yang baik didapat dari ketepatan dalam pengaturan benda yang akan dipotret dan sudut pengambilannya (angle). Properti berkaitan dengan penambahan benda-benda yang yang dipilih untuk menimbulkan kesan tertentu yang ingin ditampilkan dalam foto yang akan dibuat. Dalam Still life photography, benda mati 
merupakan objek utamanya sehingga fotografer harus benar-benar mengenali karakter serta tekstur dari benda yang akan difoto. Keunggulan Still life photography tidak perlu menggunkan kamera digital yang mahal. Tidak harus menggunakan kamera DSLR/LSR dengan lensa makro,bahkan kamera poket/tustel4 dan kamera lensa ultra wide bisa digunakan.

\section{Food Photography}

Perkembangan Industri kuliner berpengaruh juga dalam perkembangan kreatifitas dunia fotografi.Fotografi makanan yang diciptakan oleh seorang fotografer professional tidak hanya menghasilkan foto yang enak dilihat, tetapi juga foto yang membangkitkan selera dan menyeragamkan persepsi.Beberapa hal yang perlu diperhatikan saat memotret makanan menurut Sari tarigan yaitu:

- Kesuaian tema dengan jenis makanan yang dipilih

- Menonjoklan bagian yang istimewa dari makanan yang akan difoto.

- Cara penyajian dari makanan yang akan difoto.

- Bereksperimen dalam mengatur tata letak makanan yang akan difoto.

(http://fotografi. upi.edu, 2016)

\section{PEMBAHASAN}

Perancangan buku ditujukan kepada pemu- da dan pemudi dengan rentang umur 21 - 30 tahun, tingkat pendidikan universitas, sarjana, atau pekerja kantoran dengan pendapatan atau uang saku per bulan kira-kira Rp. 3.000.000,00 - Rp. 5.000.000,00. Pemuda dan pemudi yang memiliki ketergantungan pada teknologi, internet, dan media sosial, serta biasa mengunjungi mall atau café, suka makan, memiliki ketertarikan, dan peduli pada upaya pelestarian kuliner tradisional Indonesia. Sehingga positioning dari buku ini adalah sebagai buku resep kuliner tradisional Indonesia bagi anak muda; yang memberikan informasi tentang 30 IKTI yang didesain modern, spontan, segar, bersih dan ringan.

Konsep komunikasi perancangan media buku adalah mengemas dengan 30 IKTI dengan deskripsi, sejarah, resep, cerita-cerita dibalik kuliner yang diharapkan mampu meningkatkan apresiasi anak muda terhadap kuliner tradisional Indonesia. 
Konsep kreatifnya adalah dengan merancang sebuah buku resep yang berbentuk menyerupai jurnal memasak dengan menggunakan teknik layout kolase pada foto dan ilustrasi corak Dekoratif dan teknik pewarnaan cat air, untuk memberikan kesan 'handmade' dan menggunakanhuruf berjenis scriptuntuk memberikan kesan 'handwritten'. Warna-warna yang digunakan dalam buku adalah warna yang sering muncul dalam makanan-makanan yang termasuk dalam $30 \mathrm{IKTI}$, seperti warna coklat, hijau, kuning, dan jingga. Selain itu digunakan juga warna merah sebagai lambang identitas Indonesia, dan warna latar belakang putih untuk memberikan kesan clean dan modern. Secara keseluruhan Kesan yang ingin ditampilkan oleh buku resep $30 \mathrm{IKTI}$ ini adalah kesan yang modern, spontan, segar, bersih dan ringan.

Konsep media terbagi atas media utama dan media pendukung.Media utama yang dipergunakan untuk menyajikan 30 IKTI adalah media buku.Namun buku ini tidak dapat berdiri sendiri. Untuk mempromosikan buku kepada target sasaran dibutuhkan media pendukung yang mudah diakses dimana saja dan kapan saja oleh target utama, seperti website dan media sosial. Selain itu, media lain seperti merchandiseyang diberikan sebagai pengingat tentang 30 IKTI dan untuk meningkatkan kebanggaan dan rasa cinta generasi muda terhadap kuliner tradisional Indonesia.

Dibawa ini adalah hasil karya dari Perancangan:

\section{a. Media Utama}

Media buku dipilih sebagai media utama

karena buku cetak berperan lebih besar dalam memberikan memori jangka panjang pada pembaca. Beberapa visual dalam desain buku antara lain adalah sebagai berikut: 


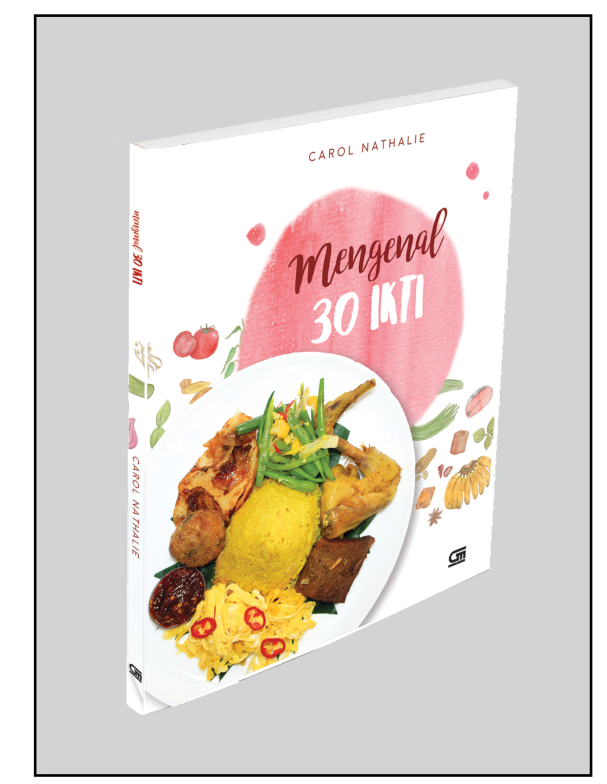

Gambar 1. Cover Depan Buku "Mengenal 30 IKTI" (Sumber: hasil karya pribadi

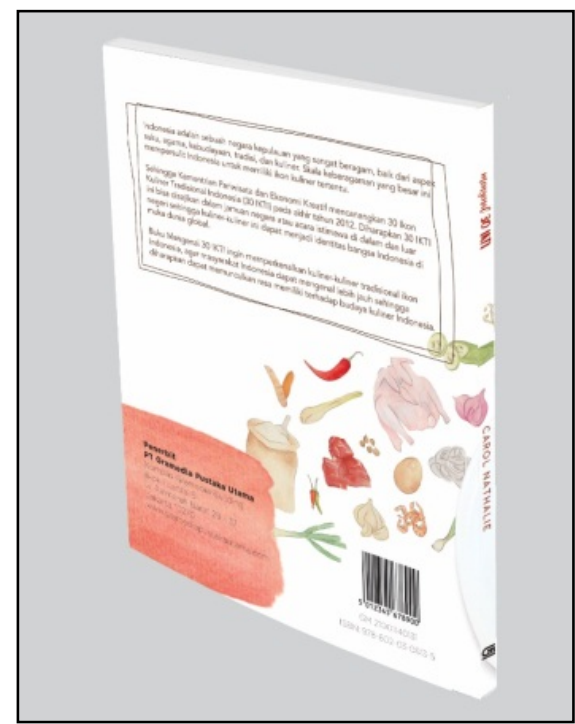

Gambar 2. Cover BelakangBuku “Mengenal $30 \mathrm{IKTI}$ (Sumber: hasil karya pribadi)

Buku kuliner ini terdiri empat bab, yaitu bab yang membahas tentang makanan utama, bab tentang makanan penutup, bab makanan camilan dan bab tentang beraneka minuman. Masing-masing bab memuat beragam kuliner unggulan tradisi Indonesia.

Pengelompokkan ini dibuat untuk mem- permudah pembaca mencari makanan tertentu dalam buku, sedangkan untuk kepentingan navigasi dan estetika, maka setiap halaman-halaman bab 
pemisah dalam buku dibuat berbeda dengan halaman isinya agar pembaca sadar ketika memasuki bab yang baru. Pembedaan dilakukan melalui desain tata letak yang menyerupai motif/pola kain menggunakan ilustrasi bahan makanan atau minuman yang digunakan dalam kuliner-kuliner yang terdapat di dalam bab tersebut. Tulisan sub-judul diletakkan di tengah atas halaman dengan detail background atau outline agar mampu menjelaskan hirarkinya.

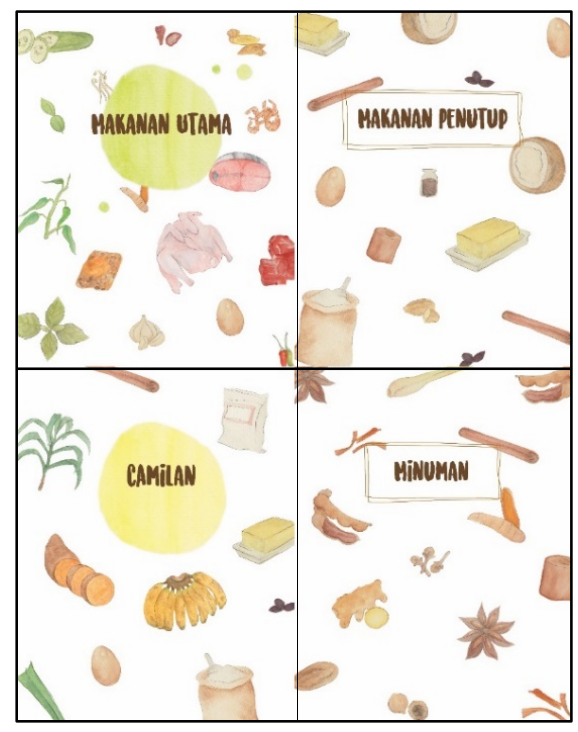

Gambar 3. Halaman Pemisah Bab Buku "Mengenal 30 IKTI" (Sumber: hasil karya pribadi)

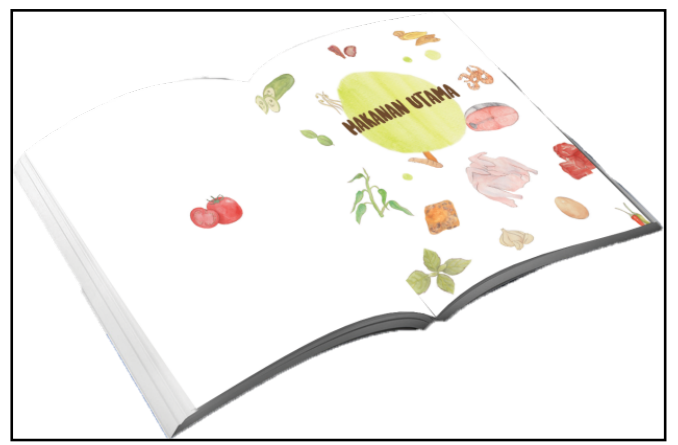

Gambar 4. Mock Up Halaman Pemisah Bab Buku"Mengenal 30 IKTI" (Sumber: hasil karya pribadi)

Pada Halaman Isi dalam buku, setiap kuliner diberi ruang berupa halaman ganda (spread) yang antara lain berisi judul atau nama makanan, daerah asal makanan, sejarah atau kisah dibaliknya, bahan dasar, bumbu halus dan cara membuatnya (resep). Pada Judul dan asal daerah makanan dibuat Ilustrasi untuk memvisualisasikan makanan yang dibahas pada halaman tersebut. Teknik 
Fotografi dipakai juga untuk menampilkan ujud makanan yang sebenarnya.Foto diambil dari sudut pandang atas untuk menyajikan informasi terinci tentang jenis makanan.Menggunakan ilustrasi corak dekoratif dengan teknik cat air untuk menggambarkan bahan baku dan bumbu dasar masakan seperti cabe, tempe, bawang merah, lengkuas dan sebagainya.Layout halaman dalam buku dibuat dengan teknik kolase terdiri dari foto, ilustrasi dekoratif dengan teknik cat air yang memberikan kesan handmade didukung dengan huruf bergaya handlettering.Gaya jurnal ini memberi kesan spontan, segar dan seakan-akan seperti catatan memasak yang merekam keberagaman kuliner unggul di tanah air.

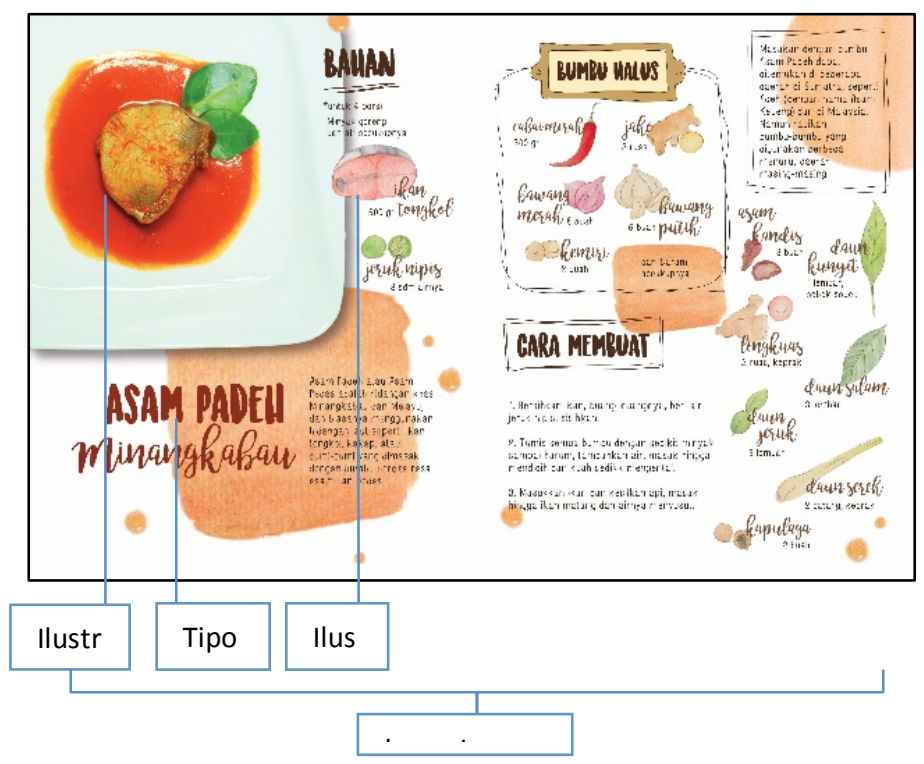

Gambar 5. Layout halaman isi - resep Rendang Padang Buku "Mencenal $30 \mathrm{IKTI}$ "

\section{b. Media Pendukung}

Buku Mengenal 30 IKTI ini perlu disosialisasikan dan dipasarkan kepada target sasaran yang telah ditentukan. Namun pemasaran melalui saluran konvensional dengan cara mendistribusikan buku dan memajangnya di toko-toko buku kini sudah kurang efektif menjangkau target sasaran. Oleh karena itu perlu ditempuh cara pemasaran yang lebih sesuai dengan saat ini, yaitu melalui media pendukung dan promosi yang menarik bagi target primer dan mudah diakses dari mana saja dan kapan saja, yang antara lain adalah sebagai berikut:

Buku ini disertai dengan booklet. Booklet dibuat sebagai pelengkap informasi yang ada di dalam buku, sebagai media informasi mengenai tempat-tempat makan atau restoran yang memang 
dikenal membuat kuliner-kuliner 30 IKTI yang enak di berbagai kota di Indonesia. Sehingga bagi pecinta wisata kuliner, mereka dapat memanfaatkan

informasi ini atau dapat dipakai sebagai referensi citarasa ketika hendak mempraktikan resep yang terdapat di dalam buku utama. Booklet dibuat versi tahunan dan akan di-update jika ada perkembangan baru.

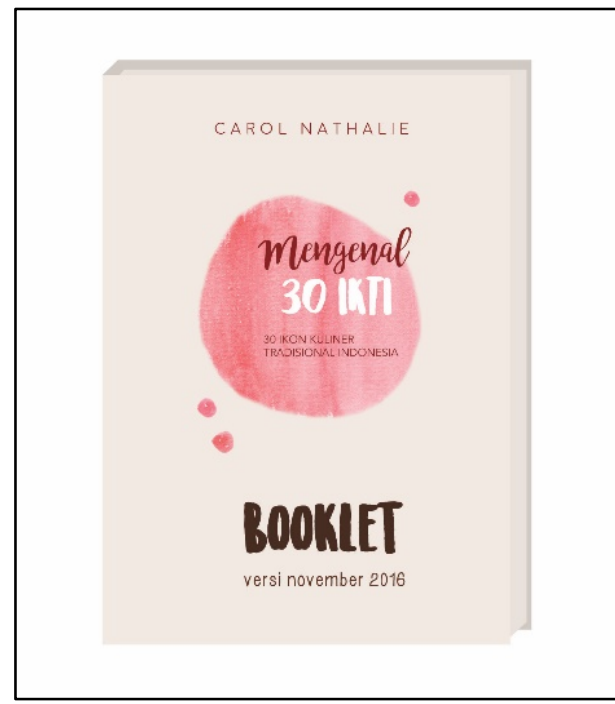

Gambar 6. Booklet "Mengenal $30 \mathrm{IKTI}$

(Sumber: hasil karya pribadi)

Website dirancang sebagai media promosi buku sekaligus media yang memberi informasi pelengkap. Konten media ini tidak sama dengan isi buku, tetapi memberikan penjelasan perihal $30 \mathrm{IKTI}$, beberapa resep makanan IKTI, dan mengarahkan pengunjung kepada buku 30 IKTI di toko online yang menjual buku dan merchandise "Mengenal $30 \mathrm{IKTI}$ ". Website dibuat dengan layout yang senada dengan buku namun agak lebih formal. Pilihan-pilihan makananmakanan yang menggunakan font seperti handwriting sehingga memiliki kesinam-bungan rupa antara website dengan buku yang ditawarkan. 


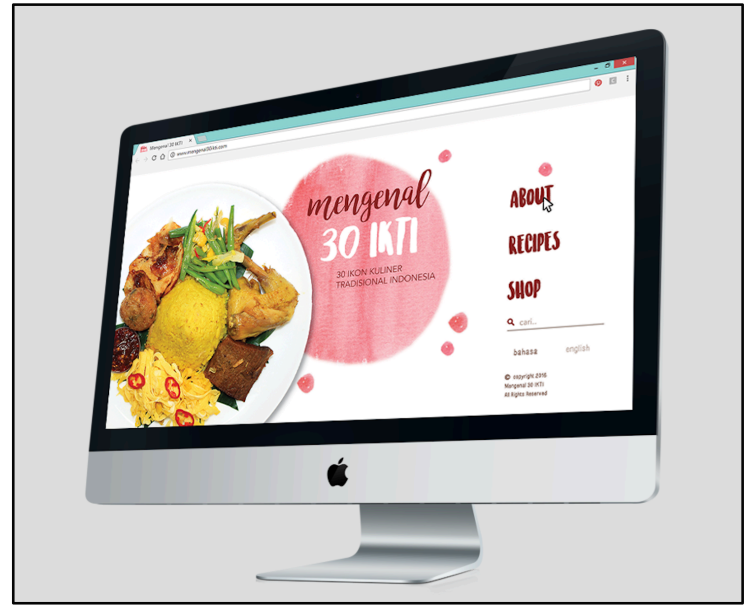

Gambar 7. Media website "Mengenal 30 IKTI" (Sumber: hasil karya pribadi)

Media lainnya yang digunakan sebagai media promosi adalah media sosial Instagram, karena fasilitas dalam media instagram ini mampu menarik opini pengikutnya seperti mengajukan pertanyaan-pertanyaan yang berhubungan dengan kuliner-kuliner $30 \mathrm{IKTI}$, asal daerah sebuah kuliner, dan lain-lain.

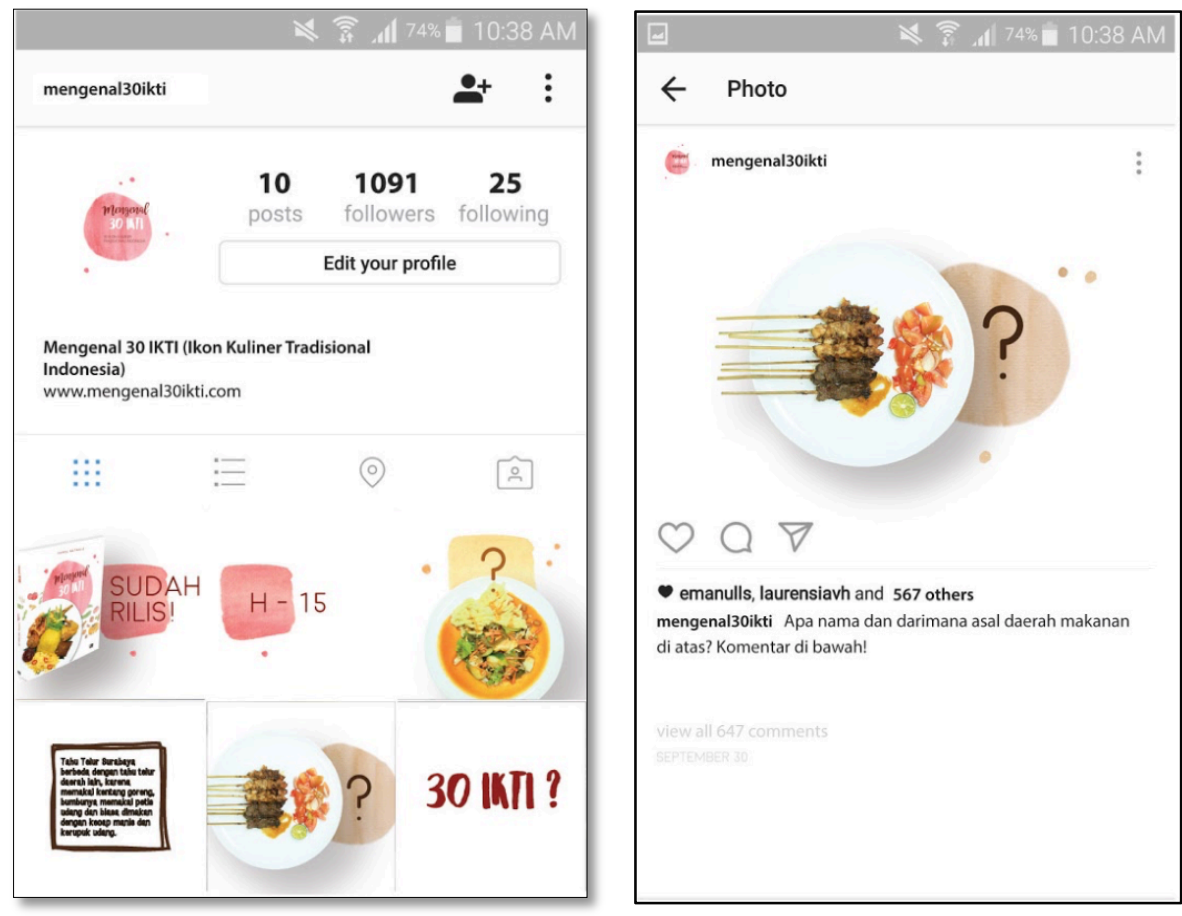

Gambar 8. Media intagram

"Mengenal $30 \mathrm{IKTI} "$

(Sumber: hasil karya pribadi) 


\section{Merchandise}

Kelompok media pendukung terakhir adalah desain merchandise. Merchandise yang dibuat digunakan sebagai pengingat akan 30 IKTI dan juga berfungsi untuk meningkatkan kebanggan dan rasa cinta generasi mudaterhadap kuliner tradisional Indonesia. Merchandise adalah celemek, mini notebook, tote bag dan mugsebagai gimmick yang dibagikan kepada pengunjung.
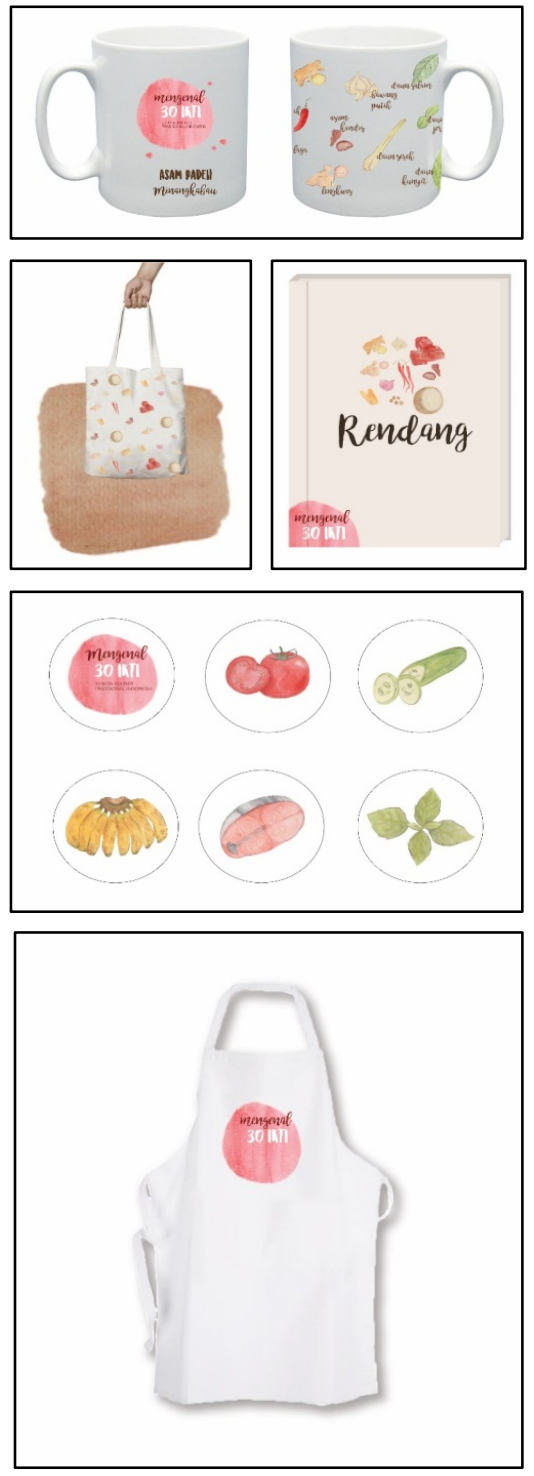

Gambar 9. Merchandise "Mengenal 30 IKTI" (Sumber: hasil karya pribadi) 


\section{PENUTUP}

Kesimpulan yang didapatkan dari peran- cangan ini adalah dalam upaya pelestarian kuliner tradisional Indonesia, tentu saja harus dilakukan melalui berbagai pendekatan yang sesuai dengan minat target dan tepat sasaran.Buku yang merupakan media informasi untuk memori jangka panjang yang dirancang dengan memperhatikan aspek fungsional dan estetika diharapkan sesuai.

Buku resep masakan $30 \mathrm{IKTI}$ dibuat dengan kesan yang akrab, modern, spontan, segar, bersih dan ringan. Menggunakan layout kolase yang menggabungkan fotografi dan teknik ilustrasidekoratif cat air yang memiliki stilasi bentuk, tanpa meninggalkan ciri khas atau karakter bentuk aslinya digunakan agar tidak menghilangkanidentitas dari makanan dan bahan-bahan pembuatannya, sehingga informasi yang disampaikan sampai secara utuh dan mudah dimengerti oleh pembaca.

Media pendukung juga diperlukan untuk mempromosikan media utama. Media pendukung memilih media yang dekat dengan anak muda saat ini seperti social media instagram, website, booklet dan merchandise.

Diharapkan dengan adanya buku resep yang didesain dalam bentuk jurnal dan gaya yang sesuai dengan anak muda saat ini sebagai media utama dan media pendukung, 30 lkon Kuliner Tradisional Indonesia dapat dikenal lebih lagi oleh generasi muda, sehingga mereka mempunyairasa memiliki dan bangga terhadap kuliner tradisional Indonesia.

\section{DAFTAR PUSTAKA}

Haslam, Andrew. (2006). Book Design. London: Laurence King Publishing Ltd.

Margono, Tri Edy dan Abdul Aziz. (2010). Mari Belajar Seni Rupa. Jakarta: Pusat Kurikulum dan Perbukuan Kementerian Pendidikan Nasional.

Purwanto, Drs. Ngalim M. (2004). Psikologi Pendidikan. Bandung: Rosda.

Santoso, Sigit. (2002). Advertising Guide Book. Jakarta: PT. Gramedia Pustaka Utama.

Susanto, A.B. (2001). Potret-Potret Gaya Hidup Metropolis. Jakarta: Penerbit Buku Kompas.

Tempo. (2015). Antropologi Kuliner Nusantara. Jakarta: Kepustakaan Populer Gramedia 


\section{Sumber Online}

Elbogory, Kemal. (2015). "Festival Makanan Tradisional; Upaya Mengenalkan Warisan Leluhur", (Online),_http://www.kompasiana.com, diunduh 16 Juli 2016).

Fadhlin, Natashi. (2012). "Empat Teknik Dasar Fotografi", (Online), (http:// www.nathasi.com/empat-teknik-dasar-fotografi, diunduh 27 September 2016).

Harnowo, Putro Agus. (2012). "Otak Lebih Sulit Ingat Bacaan Buku Digital Daripada Buku Cetak". (Online), (http://health.detik.com/read/2012/03/15/165350/1868485/763/otak-lebihsulit-ingat-bacaan-buku-digital-daripada-buku-cetak, diunduh 23 Agustus 2016).

Koenne, Ada Henne. (1996). "Culinary Reconnaissance Indonesia", (Online), (http://archive.aramcoworld.com/, diunduh tanggal 22 Agustus 2016).

Sekolah Jurnalistik dan Multimedia (SJM). (2010). "Pengertian dan Sejarah Fotografi", (Online), (http://www.sjm.sch.id/p/pengertian-dan-sejarah-fotografi.html, diunduh 27 September 2016).

Suhadha, Abdul Karim dan Dicky Aprisandy Fatah. "Still Life Photography", (Online), (http://fotografi.upi.edu/home/6-keahlian-khusus/still-life-photography).

Windratie. (2015). “Ke Mana '30 Ikon Kuliner Tradisional Indonesia' Sekarang?",(Online),(http://www.cnnindonesia.com/, diakses 30 Agustus 2016).

Winneke, Odilia. (2008). "William Wongso: Terobsesi Makanan Indonesia", (Online), (http://food.detik.com/read/2008/08/12/103037/986966/549/william-wongso-terobsesimakanan-indonesia, diakses 30 Agustus 2016. 